\title{
Genética da conservação aplicada ao tráfico ilegal de aves*
}

\section{Conservation genetics applied to birds illegal trade}

\author{
Gonçalves, BP'; Wasko, AP²
}

\begin{abstract}
Gonçalves, BP; Wasko, AP. Genética da conservação aplicada ao tráfico ilegal de aves. Saúde, Ética \& Justiça. 2013;18(Ed. Especial):79-83.

RESUMO: Entre os animais silvestres envolvidos em tráfico/comércio ilegal no Brasil, as aves compreendem um dos grupos mais atingidos, especialmente devido a características como canto e colorido das penas. Atualmente, análises genéticas compreendem uma das formas mais eficazes de gerar dados para solucionar e minimizar os resultados de crimes ambientais e comércio ilegal de animais silvestres. Uma das análises genéticas que podem ser utilizadas com o intuito de subsidiar programas conservacionistas associados ao tráfico ilegal de aves refere-se à sexagem molecular, dado que neste grupo de vertebrados nem sempre é possível identificar o gênero por meio de caracteres morfológicos. A sexagem molecular pode ser feita com base em amostras de DNA obtidas de diferentes fontes, como penas e sangue, e posterior amplificação de regiões dos genes CHD-Z e CHD-W (chromo helicase-DNA binding). Os dados de perfis genéticos sexoespecíficos servem de subsídio a programas conservacionistas de manutenção e/ou reprodução em cativeiro e posterior soltura ou reintrodução dos animais em ambiente natural.
\end{abstract}

PALAVRAS-CHAVE: Aves; Sexagem; Genética da conservação; Tráfico.

\footnotetext{
* Este trabalho é relacionado à revisão bibliográfica da dissertação de mestrado da aluna Bianca Picado Gonçalves.

${ }^{1}$ Bióloga, Professora Assistente Doutora do Departamento de Genética, Instituto de Biociências, UNESP.

${ }^{2}$ Bióloga, Aluna de Mestrado do Programa de Pós-Graduação em Ciências Biológicas (Genética), Instituto de Biociências, UNESP.

Endereço para Correspondência: Adriane Pinto Wasko, Departamento de Genética, Instituto de Biociências, Universidade Estadual Paulista - UNESP, Botucatu, SP. CEP 18618-970. E-mail: awasko@ibb.unesp.br
} 


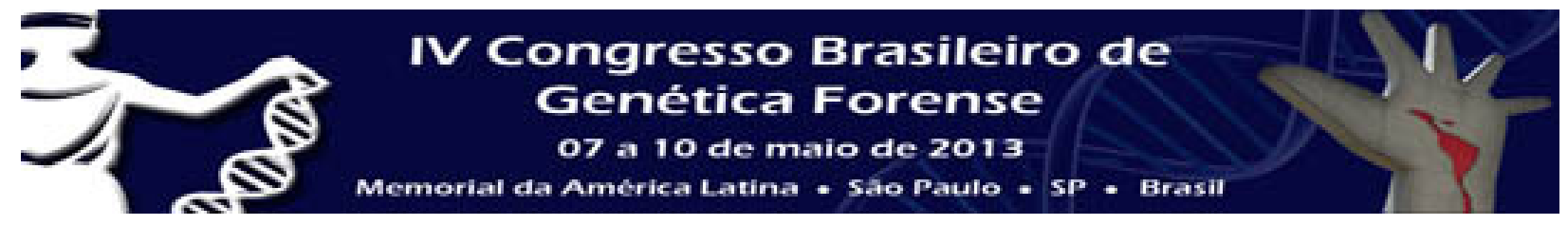

\section{INTRODUÇÃO}

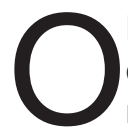

Brasil possui uma extraordinária biodiversidade, apresentando o maior número de espécies conhecidas de mamíferos, peixes dulcícolas, anfíbios e plantas superiores. Além disso, abriga uma das mais diversas avifaunas do mundo, sendo o número de espécies estimado em cerca 1.800. Adicionalmente, aproximadamente 240 espécies de aves são endêmicas, tendo uma distribuição geográfica restrita ao Bra$\mathrm{sil}^{1,2}$. A despeito desta grande diversidade de aves em todos os biomas brasileiros, intervenções humanas, especialmente associadas à destruição e/ ou fragmentação de habitats e mudanças climáticas, têm tido impactos negativos nas populações, uma vez que diminuem a disponibilidade de recursos e modificam as condições de seus ambientes ${ }^{3,4}$.

Os resultados desses impactos podem ser claramente visualizados pelo número de espécies de aves ameaçadas de extinção, sendo o Brasil o país que apresenta o maior número de espécies neotropicais categorizadas como "criticamente em perigo", "em perigo" ou "vulnerável"5,6. Adicionalmente, o tráfico ilegal de animais silvestres (naturais de determinado país ou região, pertencentes às espécies nativas, migratórias, aquáticas ou terrestres, que tenham a sua vida ou parte dela ocorrendo naturalmente dentro dos limites do território nacional e suas águas jurisdicionais), definido pela retirada de espécimes de vida livre para que possam ser comercializados, é também responsável pela ameaça de diversas espécies de aves no Brasil?.

\section{TRÁFICO DE ANIMAIS SILVESTRES}

Estima-se que o comércio ilegal de animais silvestres movimente anualmente de 10 a 20 bilhões de dólares no mundo ${ }^{8}$, sendo considerado a terceira maior atividade ilegal, após os tráficos de armas e narcóticos ${ }^{9}$. Devido especialmente a sua grande biodiversidade, o Brasil é responsável por cerca de 10 a $15 \%$ do valor total mundial do tráfico de animais silvestres. Este tráfico é estruturado sobre uma rede formada por um emaranhado de rotas para o escoamento de animais no interior do Brasil e também para fora do país ${ }^{10}$. Nas Regiões Norte, Nordeste e Centro-Oeste do país, ocorre um expressivo número de ocorrências de captura de animais silvestres que são posteriormente destinados a centros urbanos por intermédio de meios ilegais. Estes animais são levados principalmente para a região Sudeste, em especial São Paulo e Rio de Janeiro, de onde, muitas vezes, partirão para abastecer o comércio ilegal internacional ${ }^{11,12}$. Segundo Giovanini ${ }^{13}$, existem quatro modalidades básicas de comércio ilegal de animais silvestres no país - (1) animais para colecionadores particulares e zoológicos - o mais cruel dos tipos de tráfico da vida selvagem, pois prioriza principalmente as espécies mais ameaçadas; (2) animais para fins científicos (biopirataria) - neste grupo, encontram-se as espécies que fornecem substâncias químicas que servem como base para a pesquisa e produção de medicamentos, movimentando altos valores; (3) animais para pet shops - modalidade que mais incentiva o tráfico de animais silvestres no Brasil, tendo como objetivo final a população em geral; (4) produtos de fauna - usados para fabricar adornos e artesanatos, como couros, peles, penas, garras e presas, entre outros.

Entre os diversos animais que têm sido envolvidos em crimes ambientais no país e apreendidos por órgãos de fiscalização, as aves compreendem um dos grupos mais atingidos, especialmente devido a seu alto valor de mercado associado ao canto e ao exuberante colorido das penas ${ }^{14}$. Estima-se que as aves correspondam a $80 \%$ das espécies mais associadas ao tráfico ilegal, sendo os Psittaciformes (como periquitos, papagaios e maritacas) e Passeriformes (como canário da terra, trinca ferro e cardeal da Amazônia) os grupos mais comumente apreendidos por autoridades ambientais como o IBAMA (Instituto Brasileiro do Meio Ambiente e dos Recursos Naturais Renováveis) ${ }^{15,16}$. Em tais apreensões, é comum constatar métodos não adequados de transporte dos animais, sem água e sem alimento, e procedimentos de cegar, amarrar as asas, quebrar o osso externo e pintar as penas dos animais, $\mathrm{e}$ até mesmo matar os pais para facilitar a captura dos filhotes, o que resulta em um alto número de mortes $^{17,18,19}$.

Com base nas leis e decretos associados a crimes contra animais silvestres, os órgãos de fiscalização, frente a um delito, normalmente autuam o infrator e apreendem os animais. Os animais apreendidos necessitam ser inicialmente alojados, alimentados e receber cuidados médicos-veterinários, especialmente devido os maus tratos e ao estresse a que foram submetidos. Posteriormente, há necessidade de serem incluídos em programas de manutenção e/ou reprodução em cativeiro e posterior soltura ou reintrodução ${ }^{19}$. Tais medidas podem ser realizadas por Centros de Recepção, Triagem e Reabilitação de Animais Silvestres (CETAS), Centros de Medicina e Pesquisa em Animais Silvestres (CEMPAS) e Criadouros Científicos de Fauna Silvestre, cujos objetivos relacionam-se a fins conservacionistas.

\section{CONSERVAÇÃO BIOLÓGICA E ANÁLISES GENÉTICAS}

O crescente impacto de atividades humanas 


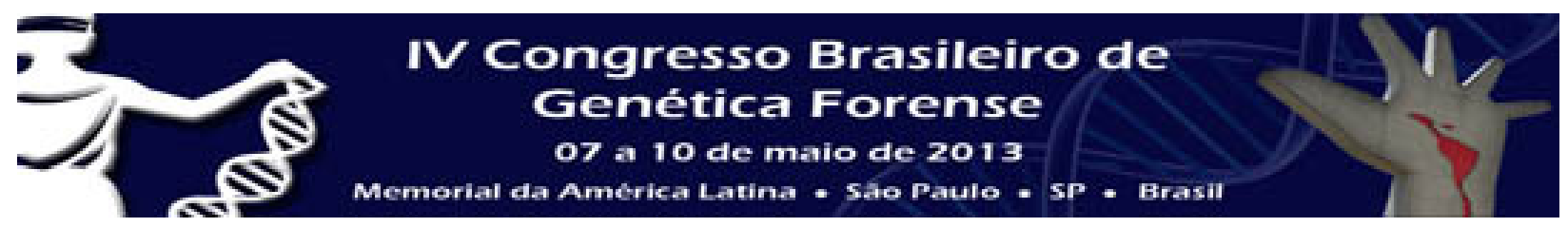

associadas à destruição de habitats e ao tráfico de animais silvestres tem levado a uma alarmante perda da biodiversidade presente em nosso planeta. Esforços no sentido de reverter ou minimizar os efeitos deste processo são ainda insuficientes e necessariamente devem envolver iniciativas integradas por campos tão diversos quanto a economia, política, ciências sociais e muitas áreas das ciências biológicas, as quais compõem uma ciência relativamente nova conhecida como biologia da conservação ${ }^{20}$. Inserida no contexto da biologia da conservação, encontra-se o campo da genética da conservação, cujos estudos baseiam-se atualmente sobretudo em análises moleculares ${ }^{21}$.

A identificação e caracterização de marcadores do genoma nuclear iniciou-se com análises de polimorfismos de comprimento de fragmentos de DNA, obtidos por meio do tratamento do DNA com enzimas de restrição, gerando padrões de RFLP (Restriction Fragment Lenght Polymorphism) ${ }^{22}$. Adicionalmente, a PCR (Polymerase Chain Reaction) ${ }^{23}$ permitiu a descrição de outros marcadores moleculares, incluindo classes de seqüências repetitivas de DNA, como os microssatélites, e de seqüências polimórficas amplificadas ao acaso (RAPD - Random Amplified Polymorphic DNA ${ }^{24}$. Atualmente, os microssatélites ou SSRs (Simple Sequence Repeats) ${ }^{25}$ representam os marcadores mais amplamente utilizados nas áreas de genética forense e populacional, dado que encontram-se distribuídos por todos o genoma e geralmente apresentam um alto grau de polimorfismo. Estes possuem a vantagem de ser co-dominantes, o que permite a identificação de heterozigotos, e podem ser analisados por meio de sua amplificação, via PCR, utilizando primers específicos complementares às seqüências únicas que os flanqueiam ${ }^{24}$. Recentemente, uma outra classe de marcador molecular, denominado de SNP (Single Nucleotide Polymorphism), ou seja, polimorfismo criado por uma mutação de ponto, resultante da substituição de um nucleotídeo por outro levando ao surgimento de diferentes alelos, vem sendo cada vez mais utilizada em análises de genética forense e conservacionista, dado seu alto grau de polimorfismo entre diferentes indivíduos tanto no DNA nuclear como no DNA mitocondrial ${ }^{26}$.

Análises forenses e conservacionistas podem, portanto, ser baseadas em análises de DNA no sentido de subsidiar problemas de questionamentos jurídico-policiais associados à conservação da biodiversidade. Estas duas vertentes apresentam uma correlação direta, no sentido de gerar dados que auxiliem, especialmente, a resolução de incertezas taxonômicas, determinação do sexo de indivíduos, minimização da perda de diversidade genética, determinação de graus de parentesco, definição de rotas de tráfico e delineamento de estratégias de recuperação de espécies e/ou populações.

\section{SEXAGEM MOLECULAR EM AVES}

A correta determinação do sexo de indivíduos é extremamente importante para elaboração e implementação de programas de manutenção e/ ou reprodução em cativeiro, reintrodução ou soltura e para estudos comportamentais. Em aves, a determinação do sexo tem especial importância, dado que aproximadamente $30 \%$ das espécies não apresentam dimorfismo sexual externo que permita a diferenciação morfológica entre machos e fêmeas. Além disso, mesmo em espécies que apresentam dimorfismo sexual tais características muitas vezes são sutis ou aparecem somente após o período de maturidade sexual, o que dificulta a correta identificação do gênero ${ }^{27}$.

Embora o sexo em aves possa ser determinado por meio de análises laparoscópicas, de esteróides fecais ou cariotípicas, tais metodologias apresentam diversas desvantagens. O exame de laparoscopia envolve grande manipulação dos animais e riscos cirúrgicos. A razão entre estrógeno e testosterona, utilizada na análise de esteróides fecais, não é altamente confiável para determinação do sexo. Por último, embora a sexagem por meio de análises cariotípicas seja adequada em aves, já que cromossomos sexuais ZW e ZZ são encontrados em fêmeas e machos, respectivamente, esta demanda grande tempo e é difícil em espécies que possuem cromossomos sexuais praticamente idênticos ${ }^{28}$.

Desta forma, a denominada "sexagem molecular" representa atualmente a forma mais eficiente de determinação do sexo em um grande número de espécies de aves. Esta pode ser feita com base em amostras de DNA obtidas de diferentes fontes, como penas e sangue que representam formas não-destrutivas de amostragem biológica em aves $^{29,30}$. Embora invasivas, as coletas de penas e de sangue implicam somente em um pequeno período de estresse aos animais, dado que é necessário realizar a contenção e a manipulação destes. Posteriormente, é realizada análise de regiões dos genes $C H D-Z$ e $C H D-W$ (chromo helicase-DNA binding), localizados nos cromossomos sexuais, para geração de perfis genéticos sexo-específicos.

O gene CHD-W localiza-se no cromossomo W e, portanto, encontra-se somente nas fêmeas, e o gene $C H D-Z$ é encontrado no cromossomo $Z$, ocorrendo em ambos os sexos ${ }^{31}$. Desta forma, a identificação do gênero pode ser realizada por meio da utilização da técnica de PCR, empregando um único conjunto de primers que se anelam a regiões 


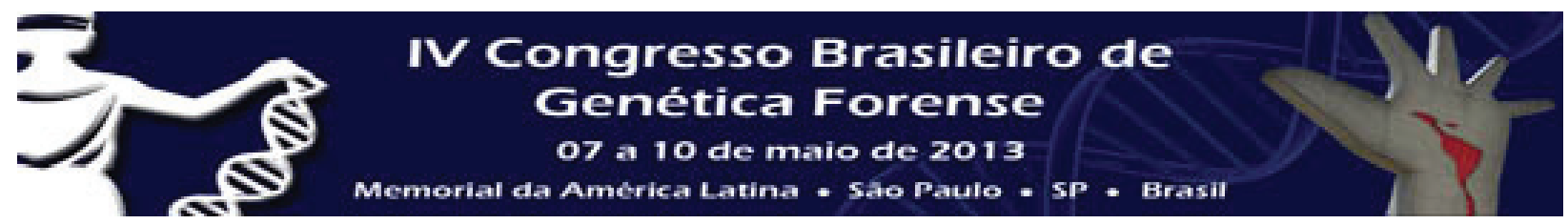

conservadas de éxons dos genes $C H D-Z$ e $C H D-W$ e amplificam uma região de íntron que difere em tamanho entre os dois genes, resultando na identificação de um fragmento de DNA em machos (genótipo homozigoto) e de dois fragmentos distintos em fêmeas (genótipo heterozigoto) ${ }^{31,32,33}$. O resultado, visualizado em gel de agarose ou poliacrilamida, demonstra que para as fêmeas, que possuem dois cromossomos sexuais diferentes, são identificados dois fragmentos de DNA, enquanto para os machos é identificado somente um fragmento (Figura 1). As maiores vantagens desta metodologia referemse a sua simplicidade, baixo custo, amostragem minimamente invasiva aos animais e uso de quantidades reduzidas de DNA ${ }^{28}$.

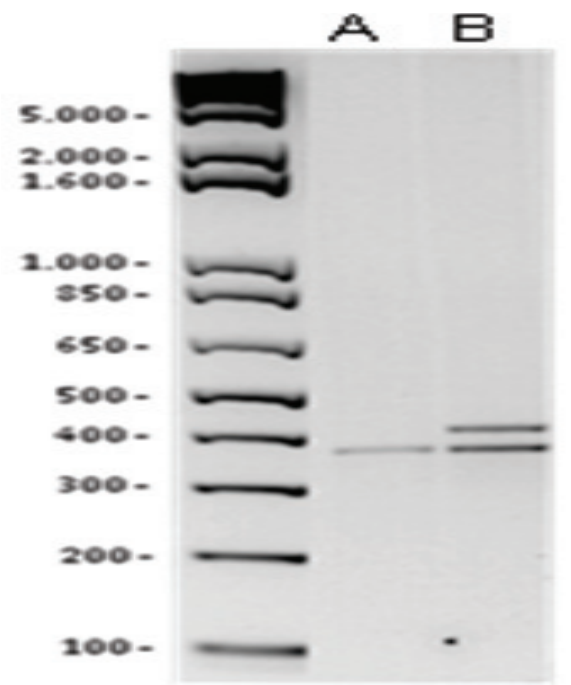

Figura 1. Perfis genéticos sexo-específicos para machos (A) e fêmeas (B) de espécies de aves, relativos à amplificação de genes $C H D-Z$ e $C H D-W$, visualizados em gel de agarose $2 \%$. À esquerda, marcador de peso molecular de $1 \mathrm{~Kb}$ (indicações em pares de bases)

Laudos de sexagem molecular podem ser obtidos junto a serviços registrados e autorizados pelo IBAMA e, na área de genética forense associada à conservação biológica, compreendem uma das principais medidas para que se obtenha sucesso em proposições de estratégias de formação de grupos ou casais objetivando a reprodução em cativeiro e/ ou uma posterior soltura ou reintrodução monitorada de indivíduos, casais ou descendentes na natureza.

\section{CONCLUSÕES}

Captura, caça, aprisionamento, transporte, compra e venda de animais silvestres, nativos ou em rota migratória, sem permissão da autoridade competente, é crime previsto na Lei Federal dos Crimes Ambientais no. 9605/98. Esta dispõe sobre as sansões penais e administrativas para os infratores, prevendo pena de prisão de seis meses a um ano, além de multa para quem desrespeitála. Apesar disso, a captura e o comércio ilegal de animais silvestres já contribuem extensivamente para a ameaça de várias espécies de aves ou populações encontradas no Brasil, como o papagaiode-peito-roxo Amazona vinacea, a arara-azul-grande Anodorhynchus hyacinthinus, a ararajuba Guaruba guarouba e o bicudo Oryzoborus maximilianî.

Por outro lado, o comércio de animais silvestres nascidos em cativeiro é também previsto em Lei Federal (Portaria 118-N/MMA-IBAMA de 15/10/1997), com o intuito de estimular a reprodução de espécies mais procuradas em criadouros regulamentados para que estes atendam as demandas do mercado, desvalorizando, assim, as ações do tráfico. Embora a reprodução de aves em cativeiro seja difícil, a utilização de dados genéticos, como os de análise de grau de parentesco e de sexagem molecular, podem subsidiar planos de formação de casais. Desta forma, a obtenção de filhotes de aves em cativeiro poderá não somente fomentar programas conservacionistas de soltura e reintrodução na natureza como também aumentar a oferta de animais a serem comercializados de forma legal no país.

Gonçalves, BP; Wasko, AP. Conservation genetics applied to birds illegal trade. Saúde, Ética \& Justiça. 2013;18(Ed. Especial):79-83. ABSTRACT: Birds represent the greater part of the animals associated to illegal trade/commerce in Brazil,
specially due to some characteristics as song and feathers colors. Nowadays, genetic analyses comprehend
one of the most efficient approaches to generate data in order to solve and minimize the results of environmental
crimes and illegal trade of wild animals. In birds, one of the genetic survey that can be used to subside conservation
plans associated to illegal trade refers to molecular sexing, since it is not possible to identify the gender in some
avian species based on morphological characters. The molecular sexing can be performed using DNA from
different samples, as feathers and blood, and further amplification of the CHD-Z e CHD-W (chromo helicase-
DNA binding) gene regions. The sex-specific genetic profiles can support conservation programs of captive
maintenance and/or reproduction and subsequent release or reintroduction of the animals on wild environment.

KEYWORDS: Birds; Sexing; Conservation Genetics; Trade. 


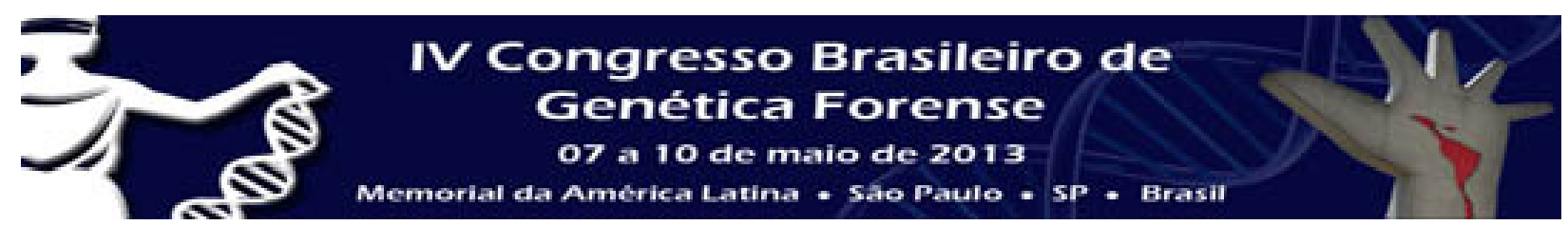

\section{REFERÊNCIAS}

1. Sabino J, Prado PIKL. Vertebrados. Brasília: Ministério do Meio Ambiente; 2004.

2. Comitê Brasileiro de Registros Ornitológicos (CBRO) [citado em mar. 2011]. Disponível em: http: www. ib.usp.br/cbro.

3. Primack RB, Rodrigues E. Biologia da conservação. Londrina, PR; 2001.

4. Segelbacher G, Cushman SA, Epperson BK, Fortin $\mathrm{M}-\mathrm{J}$, Francois O, Hardy OJ, Holderegger R, Taberlet $P$, Waits LP, Manel S. Applications of landscape genetics in conservation biology: concepts and challenges. Conserv Genet. 2010;11:375-85.

5. Collar NJ. Family Psittacidae (Parrots). In: Del Hoyo J, Elliott A, Sargatal J, editors. Handbook of the birds of the world. Barcelona: Lynux Edicions; 1997.

6. International Union for Conservation of Nature (IUCN) IUCN red list of threatened species [cited abr. 2013] Available from: http://www.redlist.org.

7. Marini MA, Garcia FI. Conservação de aves no Brasil. Megadiversidade. 2005;1:95-102.

8. Norberto G. Tráfico de animais silvestres x educação. Disponível em: http://www.zoo.ba.gov.br/upload/pdf/ artigo_gerson.pdf.

9. Webb J. Procecuting wildlife traffickers: important cases, many tools, good results. Apresentado a 1‥ Conferência Sul Americana Sobre o Comércio Ilegal de Fauna Silvestre, Brasília; 2001.

10. Hernandez TFE, Carvalho SM. O tráfico de animais silvestres no Estado do Paraná. Acta Sci Hum Soc Sci, Maringá. 2006;28:257-66.

11. Jupiara A, Anderson C. Rio é o centro internacional de traficantes de animais. O Globo, Rio de Janeiro, 21 jul. 1991

12. RENCTAS - Rede Nacional de Combate ao Tráfico de Animais Silvestres. 1ํ. Relatório nacional sobre o tráfico de fauna silvestre. Brasília: Rede Nacional de Combate ao Tráfico de Animais Silvestres; 2002.

13. Giovanini D. Diagnóstico del comercio ilegal de la fauna brasileña. In: Actitudes hacia la fauna en latinoamérica. Washington, DC: Human Society Press; 1998.

14. Pereira GA, Brito MT. Diversidade de aves silvestres comercializadas nas feiras livres da região metropolitana de Recife, Pernambuco. Atual Ornitol. 2005; $126: 14$

15. Araujo ACB, Behr ER, Longui SJ, Menezes PTS, Kanieski MR. Diagnóstico sobre a avifauna apreendida e entregue espontaneamente na região central do Rio Grande do Sul, Brasil. Braz J Biosc. 2010;8:279-84.

16. Ministério do Meio Ambiente - MMA. Secretaria de Biodiversidade e Florestas (SBF). Avaliação e ações prioritárias para a conservação da biodiversidade da mata atlântica e campos sulinos. Brasília, DF:
Ministério do Meio Ambiente; 2012.

17. Lopes PRD. Comércio de animais silvestres. Bioikos. 1991;5:49-56.

18. Toufexis A. All God's creatures priced to sell. Time. 1993;142:36-41.

19. Branco MA. Políticas públicas e serviços públicos de gestão e manejo da fauna silvestre nativa resgatada. Estudo de caso. Prefeitura da Cidade de São Paulo. São Paulo; 2008.

20. Soulé ME, Wilcox BA. Conservation biology. An evolutionary-ecological perspective. Sunderland: Sinauer Associates; 1980.

21. Avise JC. Introduction: the scope of conservation genetics. In: Conservation genetics: case histories from nature. New York; 1996.

22. Grodzicker T, Willians J, Sharp P, Sambrook J. Physical mapping of temperature sensitive mutations. Cold Spring Harbor Symp Quant Biol. 1974;39:43946.

23. Mullis K, Faloona S, Saiki G, Erlich H. Specific enzymatic amplification of DNA in vitro: the polymerase chain reaction. Cold Sping Harbor Symp Quant Biol. 1987;51:263-73.

24. Ferreira ME, Grattapaglia D. Introdução ao uso de marcadores moleculares em genética. 3a ed. Brasília, DF: EMBRAPA-CENARGEM; 1998.

25. Litt M, Luty JA. A hypervariable microsatellite revealed by in vitro amplification of adinucleotide repeat within the cardiac muscle actin gene. Am J Hum Genet. 1989;44:397-401.

26. Goodwin W, Linacre A, Hadi S. An introduction to forensic genetics. England: John Wiley \& Sons Ltda; 2007.

27. Pough FH, Janis CME, Heiser JB. A vida dos vertebrados. 3a ed. São Paulo: Atheneu; 2003.

28. Miyaki CY, Griffiths R, Orr K, Nahum LA, Pereira SL, Wajntal A. Sex identification of parrots, toucans, and curassows by PCR: perspectives for wild and captive populations studies. Zoo Biol. 1998;17:415-23.

29. Waits LP, Paetkau D. Noninvasive genetic sampling tools for wildlife biologists: a review of applications and recommendations for accurate data collection. $J$ Wildlife Manag. 2005;69:1419-33.

30. Pauli JN, Whiteman JP, Riley MD, Middleton AD. Defining noninvasive approaches for sampling of vertebrates. Cons Biol. 1999;24:349-52.

31. Griffiths R, Double MC, Orr K, Dawson RJG. A DNA test to sex most birds. Mol Ecol. 1998;7:1071-5.

32. Fridosfsson AK, Ellegren $\mathrm{H}$. Molecular evolution of the avian $C D H 1$ genes on the $Z$ and $W$ sex chromosomes. Genetics. 2000;155:1903-12.

33. Griffiths R. Sex identification in birds. Semin Avian Exotic Pet Med. 2000;9:14-26. 